\title{
SOURCE MECHANISM OF THE DEEP COLOMBIAN EARTHQUAKE OF JULY 31, 1970 FROM THE FREE OSCILLATION DATA
}

\author{
JORGE A. MENDIGUREN* and KEIITI AKI**
}

RESUMO O método proposto por Mendiguren (1977) para determinar os parâmetros da fonte, a partir de oscilaçōes livres, foi usado no caso do sismo profundo de 31 de julho de 1970, na Colombia. Os resultados indicam que a fonte se propagou horizontalmente $150 \mathrm{~km}$ ao longo da litosfera e cortou-a em toda sua espessura. A placa comporta-se como um guia para a propagação da fonte. A velocidade determinada de propagação horizontal da fonte, foi igual a $3,8 \mathrm{~km} / \mathrm{s}$. A intensidade da fonte cresceu proporcionalmente, com a distância de propagação elevada ao quadrado. Essa lei de crescimento da fonte pode ser interpretada por uma falha em forma de leque ou por uma fonte em forma conica. O deslocamento e a queda de esforço médio são estimados em $360 \mathrm{~cm}$ e 300 bárias para o modelo da falha. Para o modelo da fonte volümétrica, a deformação de cizalhamento transformacional e os esforços são estimados em $12 \times 10^{-5}$ e 160 bárias. Não há evidências de radiação de um par duplo de forçás antes do tempo de origem de $\mathrm{P}$. E demonstrado que as componentes isotrópicas e deviatóricas dọ tensor-momento não podem ser resolvidas de forma única, quando dispomos de dados de um único modo de oscilação. Observa-se que, de um ponto de vista estatístico, os dados de $\mathrm{O}^{\mathbf{s}} \mathrm{n}$ disponíveis para o sismo colombiano poderiam ser igualmente explicados por um modelo de fonte puramente deviatórica ou por uma fonte que inclua uma componente isotrópica. Experimentos numéricos indicam que a inclusão de dados de modos superiores não altera essa situação. No entanto, esses experimentos numéricos mostram que os dados disponíveis e o método usado na inversão dos dados não causariam a aparição de uma componente isotrópica nos resultados se a fonte real fosse deviatórica pura. Se o desvio de uma fonte deviatórica pura for produzido por ruído, esse ruído não pode ser aleatório, pois poderia ter sido produzido por heterogeneidades laterais não incluídas no método de inversão.

ABSTRACT The method proposed by Mendiguren (1977) to determine the source parameters from free oscillation data is applied to the July 31,1970 deep Colombian earthquake. The results indicate a source propagationg horizontally for about $150 \mathrm{~km}$ along the lithosphere and cutting across its width. The slab behaves as a guide for source propagation. The horizontal propagation velocity is determined as $3.8 \mathrm{~km} / \mathrm{sec}$. The intensity of the source grew proportionally to the second power of the propagation distance. This rate of source intensity growth may be interpreted either by a fan-shaped fault model or by a cone shaped volume source. The average slip and stress drop are estimated as $360 \mathrm{~cm}$ and $300 \mathrm{bars}$ for the fault model. For the volume source model the transformational shear strain and stress are estimated as $11 \times 10^{-5}$ and 160 bars. There is no evidence of a double couple radiation preceeding the $\mathrm{P}$ origin time. It is shown that the isotropic and deviatoric components of the moment tensor cannot be uniquely resolved when only observations of a single mode are availabe. It is observed that, from an statistical basis, the available $S_{n}$ data for the Colombian shock can be equally well explained by a pure deviatoric source model or by a source model including an isotropic component. Numerical experiments indicate that the inclusion of higher mode data does not change this situation. But, on the other hand, numerical experiments, show that the available data and the scheme used for the inversion would not result in a solution including an artificial implosive component if the actual source were pure deviatoric. If the departure from a pure deviatoric source is produced by noise, it has to be non random, as it could be produced by lateral heterogeneities not included in the inversion scheme.

* Departamento de Geociências - Universidade de Brasília - 70.000 Brasília D.F. - Brazil.

** Department of Earth and Planetary Sciences - Massachusetts, Institute of Technology - Cam. bridge, Massachusetts 02139 - USA. 
INTRODUCTION The source mechanism of deep earthquakes remains as one of the challenging unresolved problems in seismology. The present study is an attempt to find the kinematics of the source process from free oscillation data using the method proposed by Mendiguren (1977), for a large $\left(m_{1}=7.1\right)$, deep (depth $\left.651 \mathrm{~km}\right)$ Colombian earthquake of July 31,1970 . The location of the earthquake is shown in Fig. 11. The free oscillation data from this earthquake has been studied by Mendiguren $(1972,1973 a, 1973 b)$ to which we will refer as M.72, M.73a, and M.73b respectively, and by Dziewonski and Gilbert (1974) and Gilbert and Dziewonski (1975), to which we will refer as D.G.74 and G.D.75 respectively. We shall refer to the paper by Mendiguren (1977) as paper 1 .

The results of this study show that the source propagated over the horizontal distance of about $150 \mathrm{~km}$ with the velocity of about $3.8 \mathrm{~km} / \mathrm{sec}$ along a direction confined in the lithospheric slab. The observed growth of source intensity with the propagation distance suggests a rupture spreading over a fan shaped fault plane, or a volume of shear failure growing into a conical body. In either case, because of the almost vertical compression axis, the process would result in a net vertical shortening of the slab and compensatory horizontal intrusion of the slab material into the surrounding mantle.

DETERMINATION OF THE SPATIAL DISTRIBUTION OF SOURCE INTENSITY The method proposed in Paper 1 to study the source mechanism from free oscillation data, consists of a computer search for the set of source parameters maximizing the amplitude of spectral peaks obtained by stacking spectra in the "excitation criterion" scheme of M.72 and M.73a.

The method assumes a double couple point source, with known geometry derived from the $\mathbf{P}$ wave data. The source parameters to be determined are the source propagation distance, azimuth, velocity, and the source intensity as a function of the instantaneous source location.

The hypocentral parameters of $\mathbf{P}$ wave nodal plane solution for the Colombian earthquake, which adequately explained spectral details at 85 WWSS stations (M. 72 and M. 73a.), were used to compute the phase correction given by equation (9) of $\mathbf{P a}$ per 1 . The first trial was made using the following source parameters: rupture time $T_{1}=T=50$ sec., and the parameter $R_{1}=0$, which specifies the intensity function by equation (8) of Paper 1 . These parameters correspond to a constant intensity source propagating horizontally for 50 sec. The rupture length was increased from 30 to $300 \mathrm{~km}$ in steps of $30 \mathrm{~km}$ and the azimuth of source propagation was increased from $0^{\circ}$ to $360^{\circ}$ in steps of $20^{\circ}$. The data used are $S_{n},{ }_{3} S_{n},{ }_{4} S_{n}$ and ${ }_{5} S_{n}$ modes with $\mathrm{n}>30$ observed in both the vertical and colatitudinal components at 85 stations which showed well defined spectral peaks. Typical results obtained in the first trial are shown in Figs. 1 to 5. Each of these figures shows contour lines for equal amplitude of spectral peak for a certain mode obtained by stacking complex spectra after correcting for the finite source propagation. The maximum in the contour map gives the best estimate of rupture propagation distance and the azimuth. Fig. 6 shows the location of maxima for all modes under study. On the average the maximum amplitudes correspond to ruptures propagating to the SE quadrant, over the distance of approximately $150 \mathrm{~km}$. The scattering is not surprising if we consider that we are looking at oscillations with wave length 5 to 9 times larger than the source di- 
mensions. On the whole, it was encouraging to find that different modes, observed in different components and having $\mathrm{n}$ ranging from 30 to 56 rendered a consistent result.

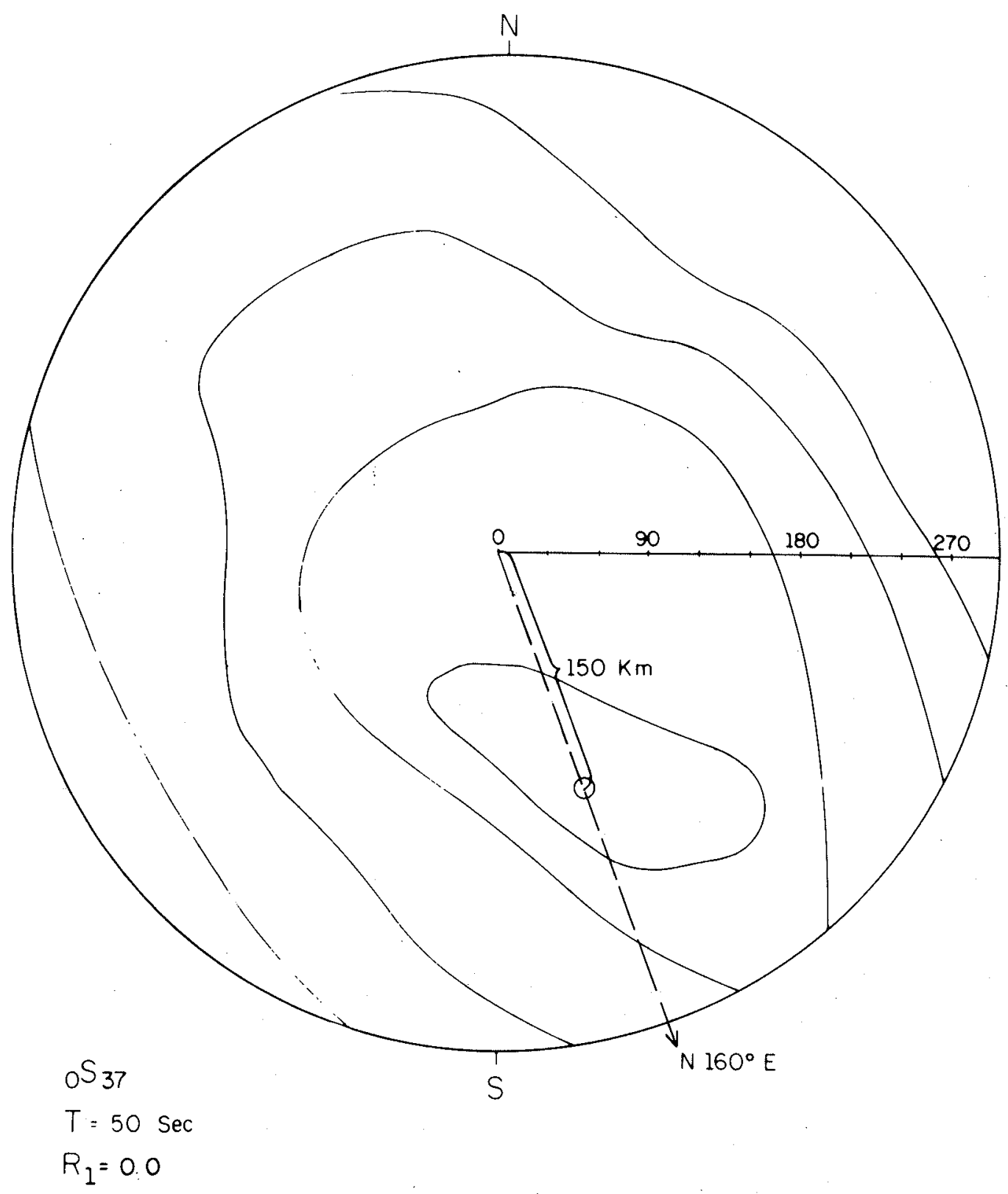

Figure 1 - Contour lines for equal amplitude of spectral peak $S_{97}$ after vectorial summation of spectra. The maximum amplitude, indicated by a small circle, was obtained for a source propagating $150 \mathrm{~km}$ in direction $\mathrm{N} 160^{\circ} \mathrm{E}$. 

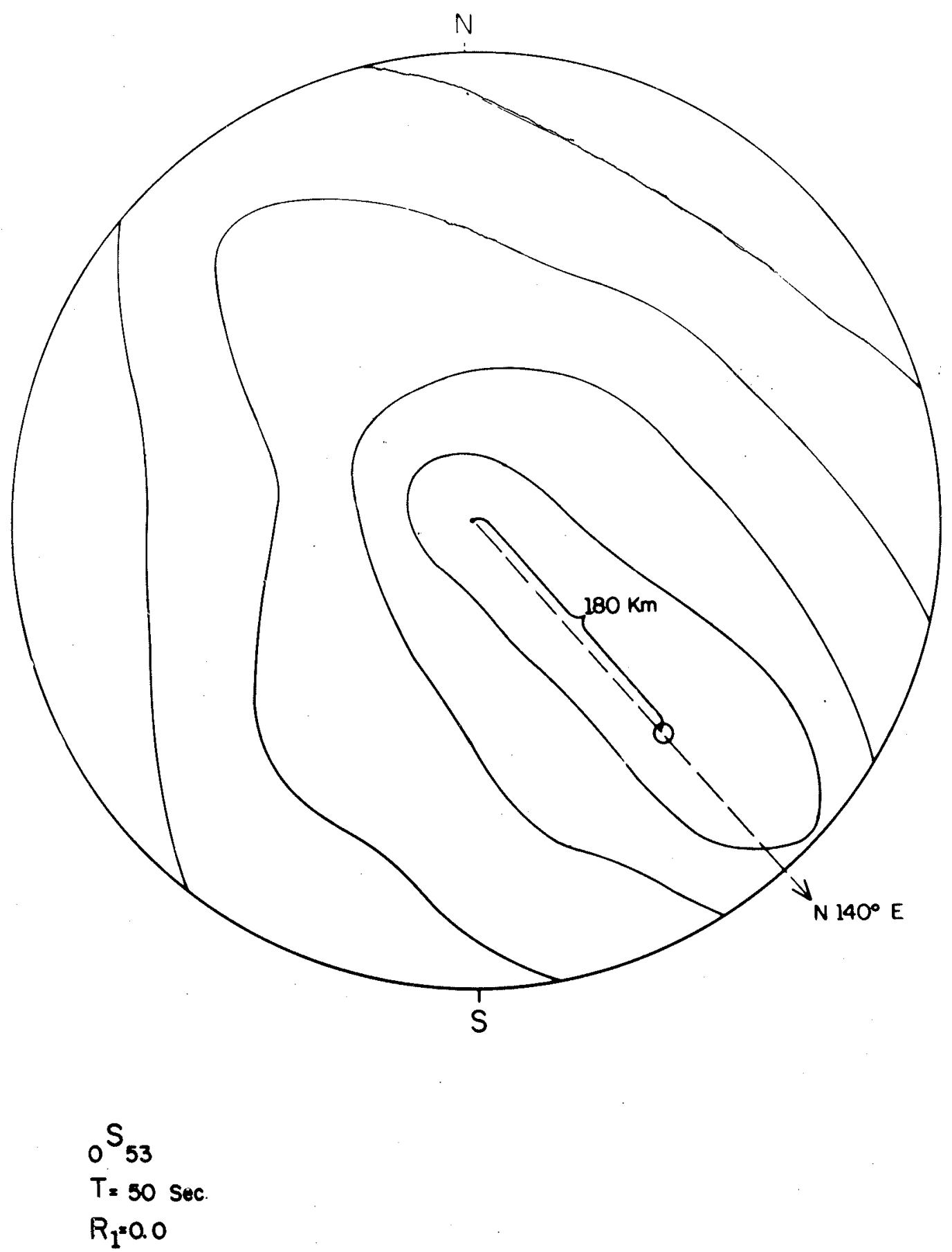

Figure 2 - See caption of Figure 1 


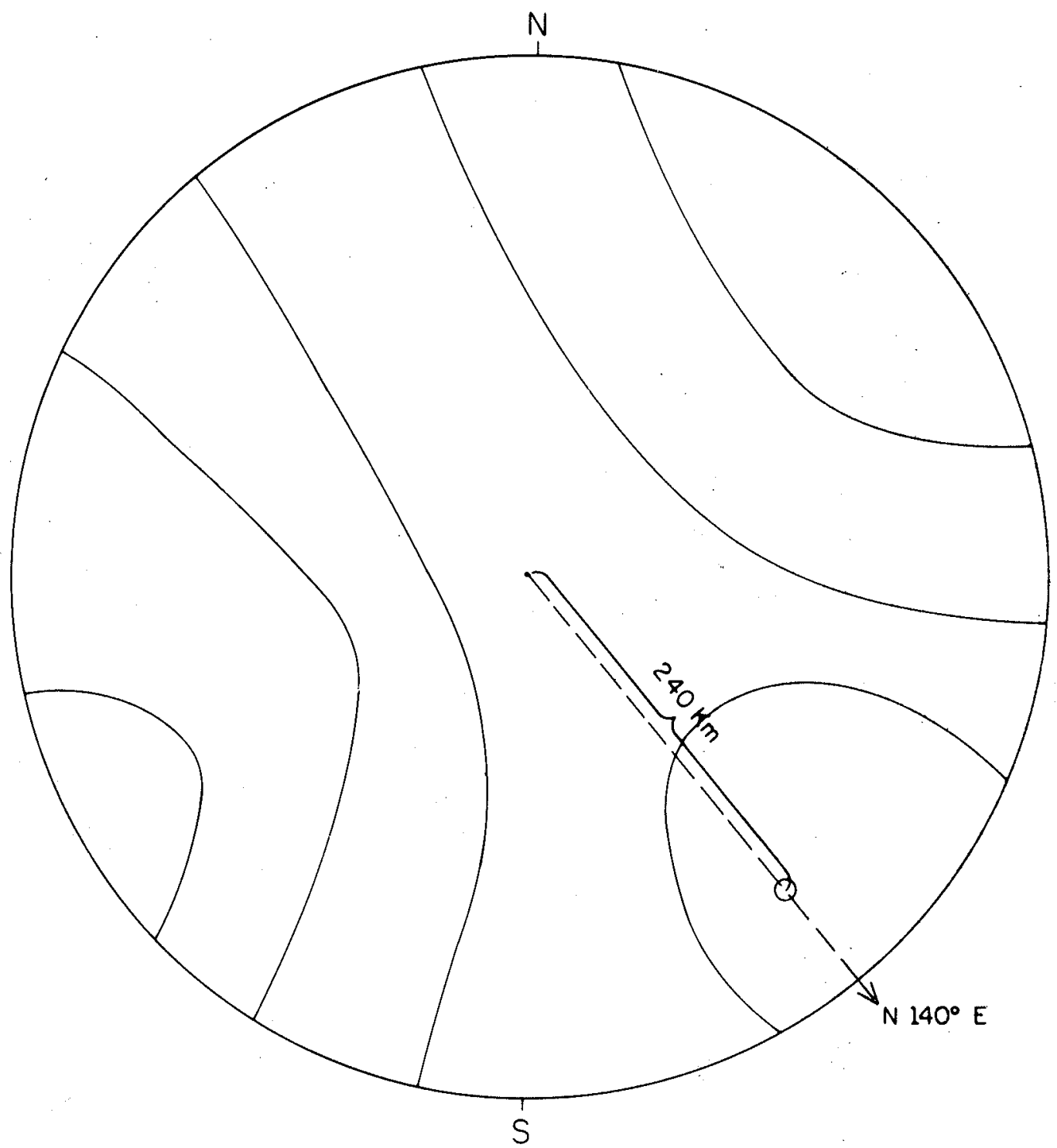

$$
\begin{aligned}
& 3_{48}^{S} \\
& T=50 \mathrm{sec} . \\
& R_{1}=0.0
\end{aligned}
$$

Figure 3 - See caption of Figure 1 


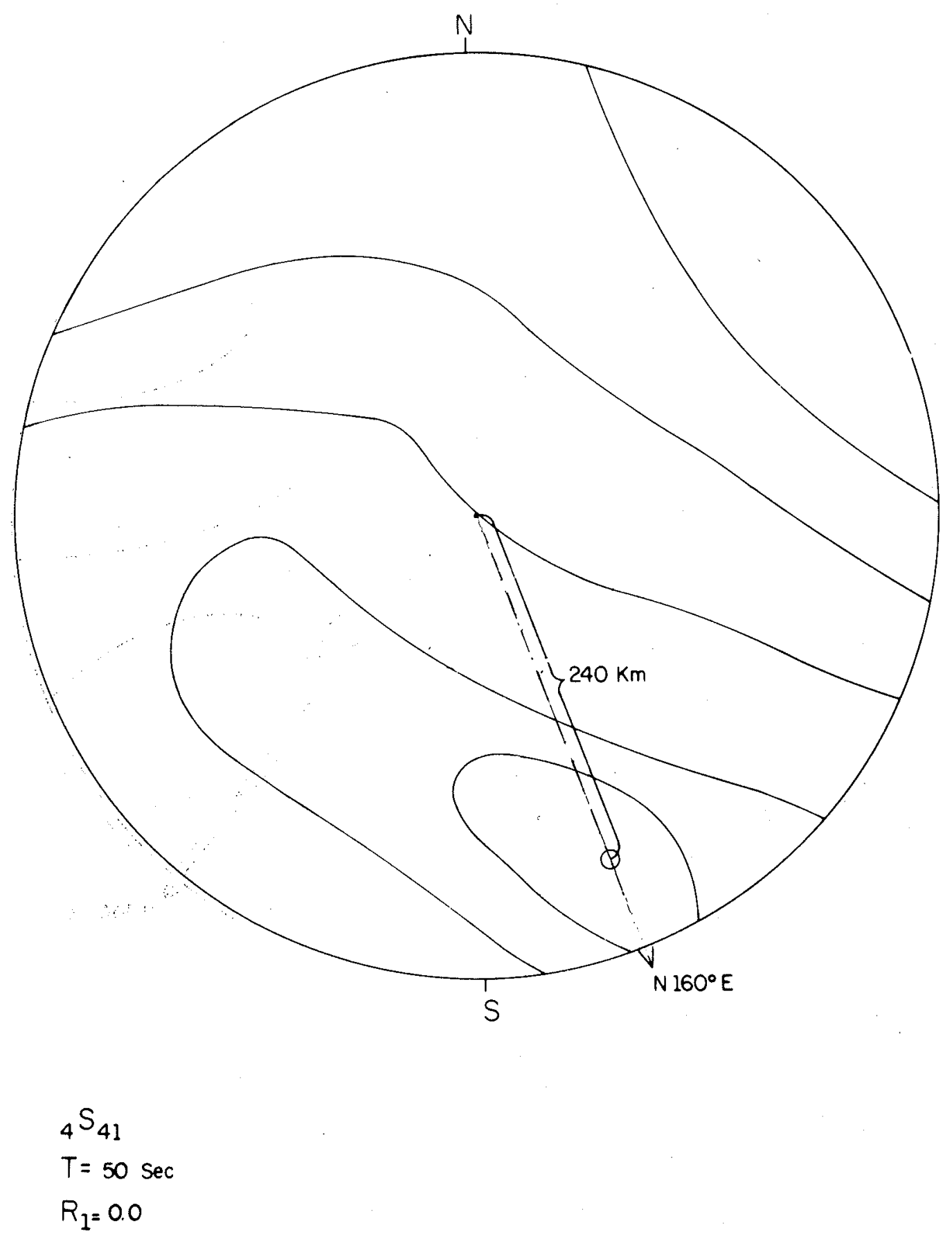

Figure $4-$ See caption of Figure 1 


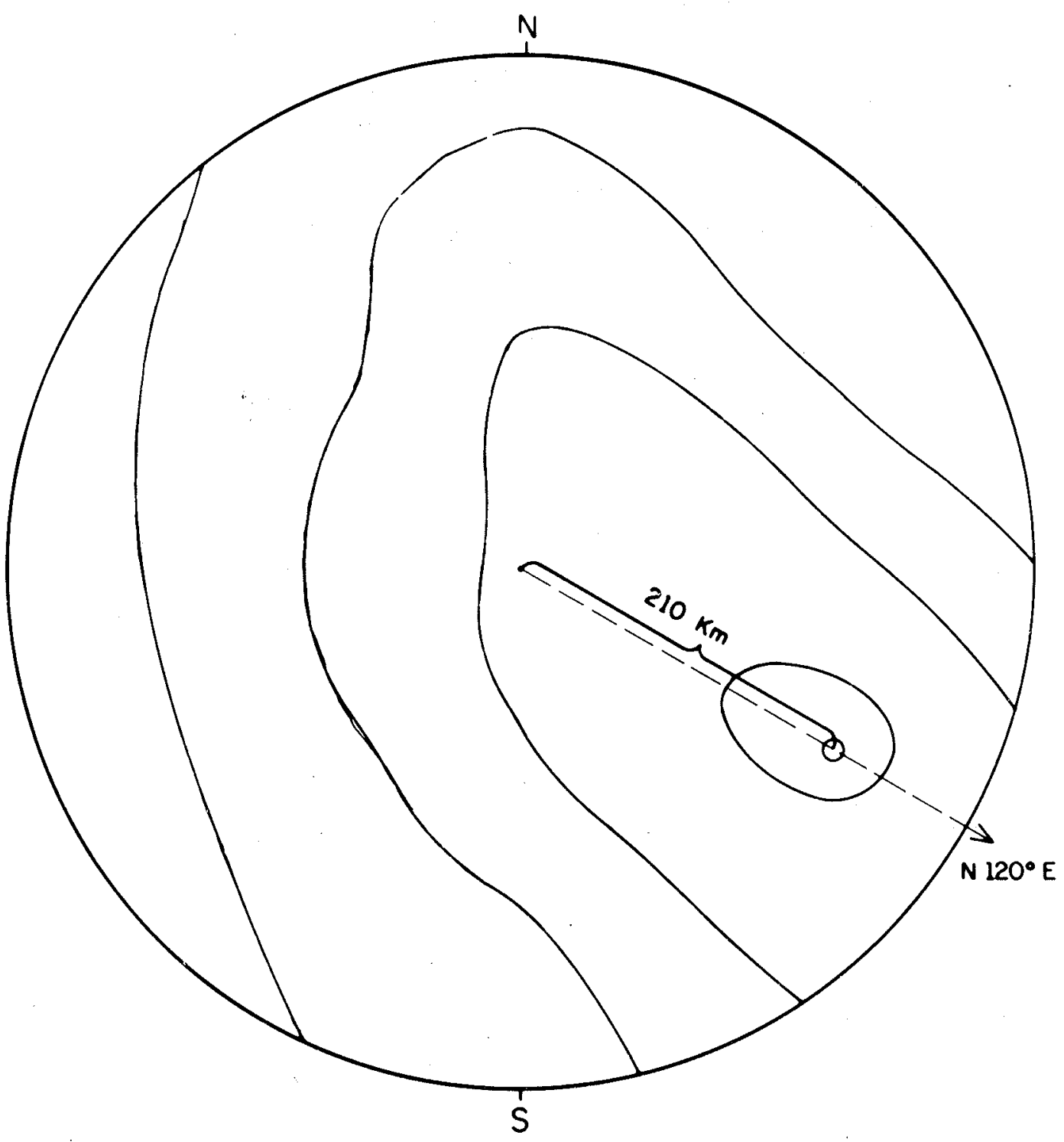

$$
\begin{aligned}
& { }_{5} S_{32} \\
& T=50 \mathrm{sec} \\
& R_{1}=00
\end{aligned}
$$

Figure 5 - See caption of Figure 1 
For a few modes two maxima were observed, while for others no maximum was observed within the range of propagation distance considered in this first trial. An actempt was made to use ${ }_{0} T_{n}$ and ${ }_{1} T_{n}$ modes but the results showed a much larger scatter than for spheroidal modes and they were considered unsuitable for deriving the source parameters. This is a probably due to the effect of lateral heterogeneity, which was shown by M.72 to be stronger on the tortional mode than on the spheroidal for the same order number. We find in Fig. 6 that the fundamental modes $S_{n}$ in general give more consistent results than higher modes. This may be due to the sensitivity of higher modes to the details of the earth's vertical structure.

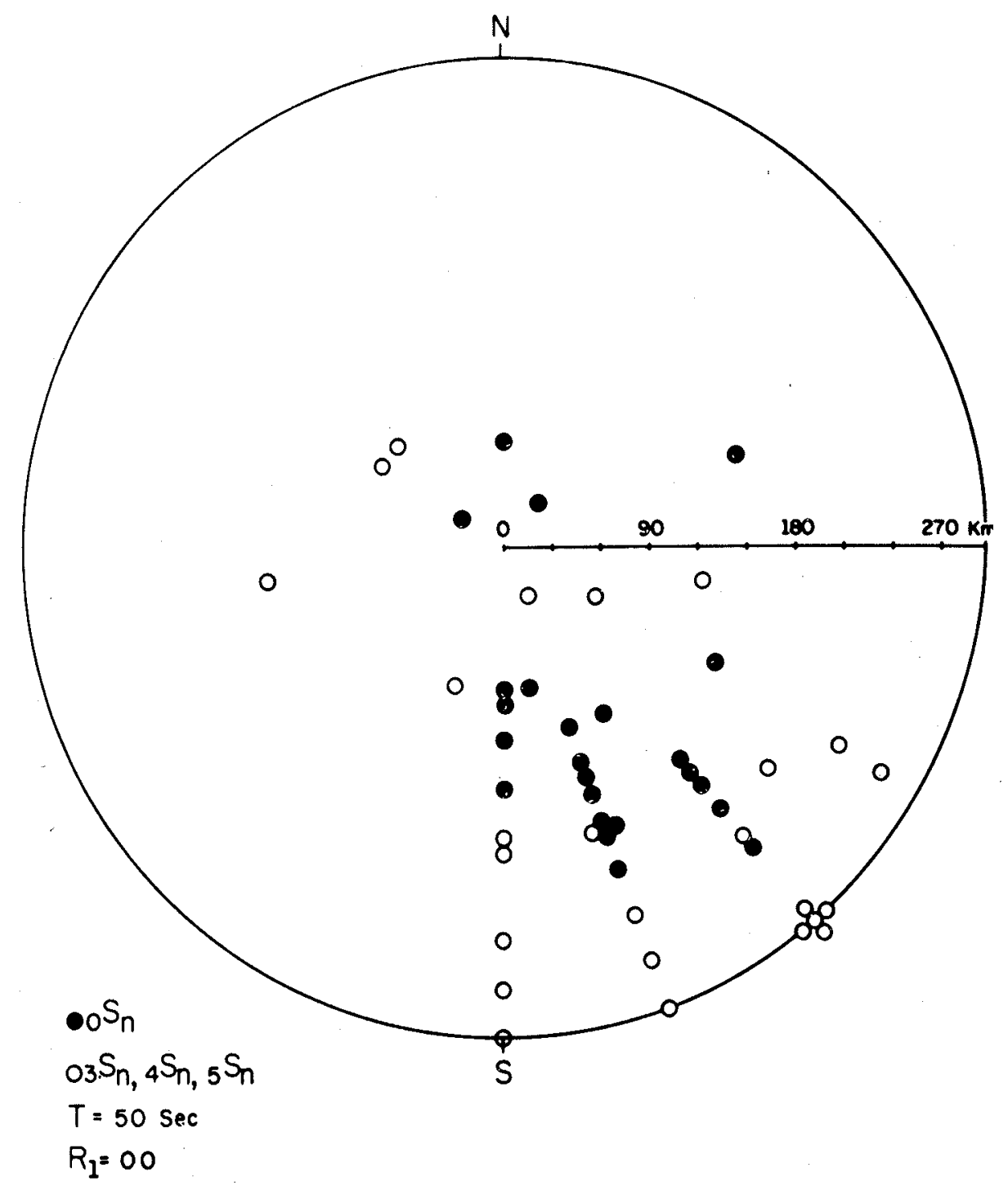

Figure 6 - Location of maximum amplitude of all modes analyzed, assuming $T=T_{1}=50$ sec and $\mathbf{R}_{1}=0$ 


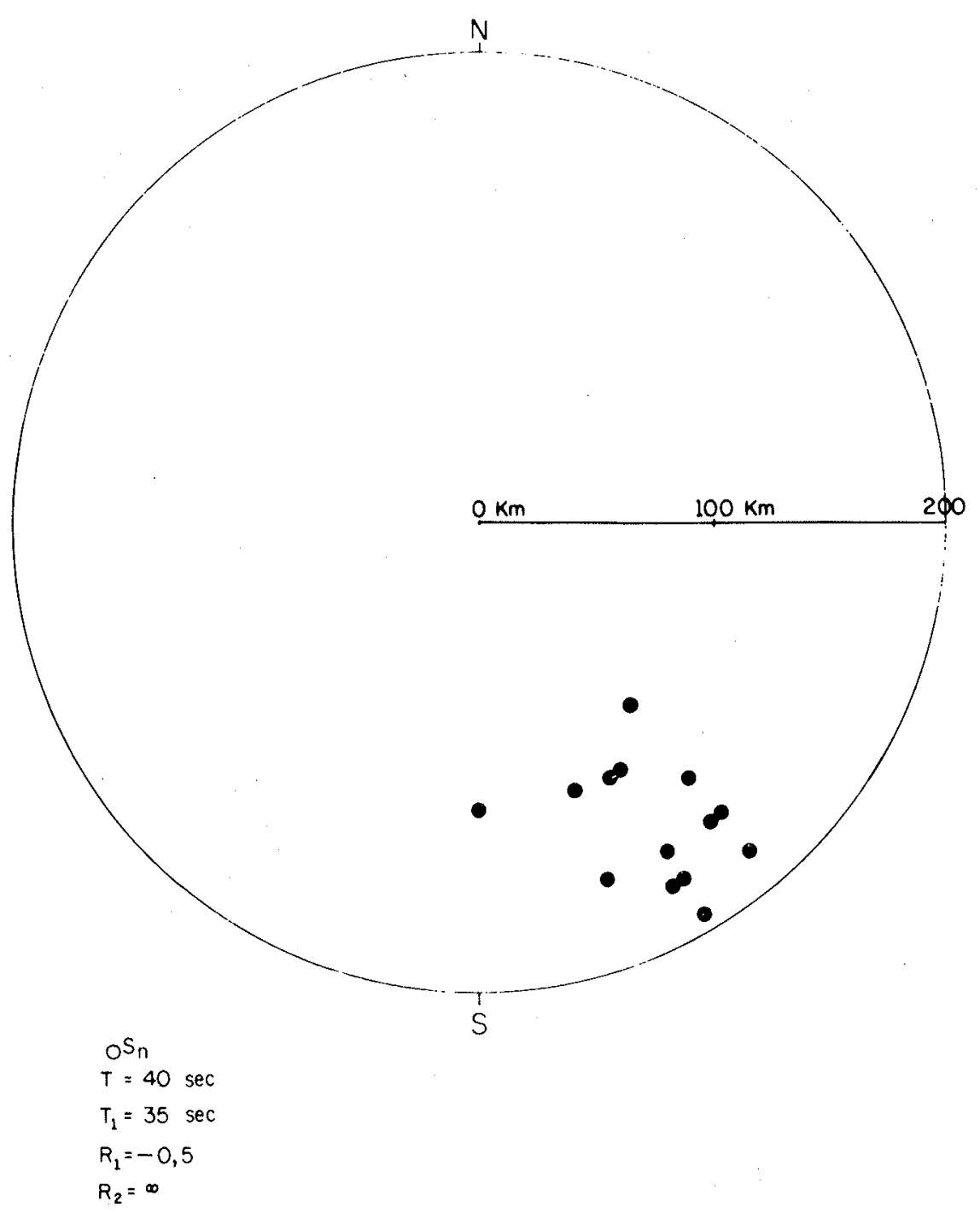

Figure 7 - Location of maximum peak amplitudes for ${ }_{11} S_{n}$ modes corresponding to final $f(s)$ parameters

From this first trial it was concluded that the rupture propagated somewhere to the SE quadrant and the propagation distance was smaller than $220 \mathrm{~km}$. Then in or. der to save computation time for further refinement of the source parameters, the data was limited to those modes rendering a well defined maximum for rupture length $\mathrm{L}$ between 100 and $200 \mathrm{~km}$ and a rupture azimuth between $110^{\circ}$ and $220^{\circ}$ in the initial trial. With that data, a computer search was made for the combination of parameters $T, T_{1}, R_{1}, R_{2}, L$, defined in Paper $l$ and rupture azimuth maximizing the amplitude of the spectral peaks. $L$ was allowed to change in steps of $10 \mathrm{~km}$ and 
the rupture azimuth in steps of $10^{\circ}$. After a few trials it became clear that the resul were converging to a model with a source intensity increasing with the propagatio distancè. The propagation distance and azimuth of maxima remained almost static nary while changing $T, T_{1}, R_{1}$ and $R_{2}$. Results among $S_{0}$ modes were again mor consistent than among higher modes. Therefore the search for details of the inten sity parameters was based only on ${ }_{0} S_{n}$ data. Finally maximum amplitude were obtai ned for parameters $T=40 \mathrm{sec}, \mathrm{T}_{1}=35 \mathrm{sec}, \mathrm{R}_{1}=-0.5$, and $\mathrm{R}_{2}=\infty$. The corres ponding shape of the intensity function is shown in Fig. 8, while the correspondin locations of maxima for $S_{n}$ modes is shown in Fig. 7. The average propagation dis tance and azimuth are $153 \mathrm{~km}$ and $N 150^{\circ} \mathrm{E}$ respectively.

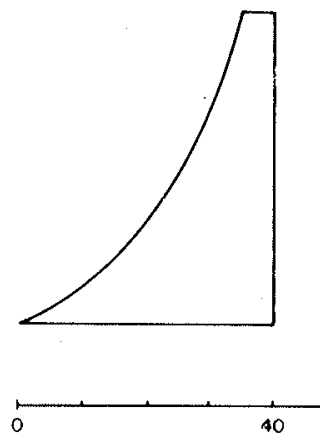

$f(1)$

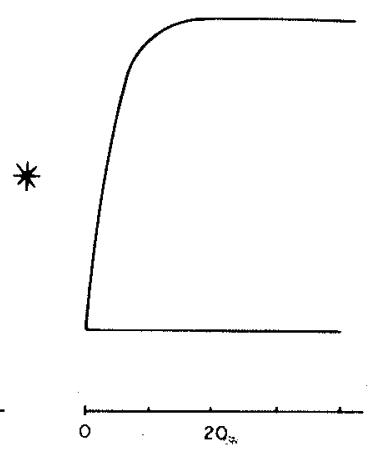

$d(t)$

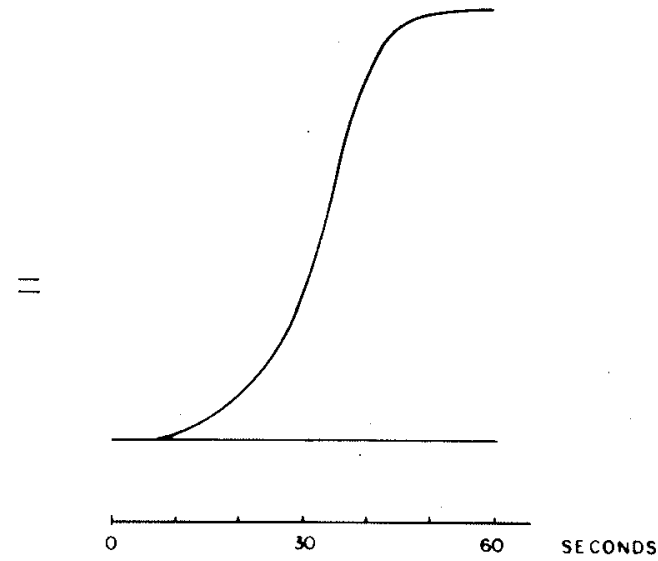

$m(t)$

Figure 8 - Source intensity function $f(t)$, dislocation time function $d(t)$ and its convolution $\mathrm{m}(\mathrm{t})$, the moment of the equivalent point double couple

Due to the characteristics of the numerical method applied, it is not simple to assess precise errors for those parameter estimates. Judging from the scattering shown in Figs. 6 and 7, and from the numerical results obtained for different source functions we conclude that the fault length and azimuth are uncertain by $\pm 30 \mathrm{~km}$ and $\pm 15^{\circ}$ respectively. Errors in the parameters of the source function will be discussed in the next section.

The parameter $R_{1}=-0.5$ corresponds to a source intensity $f(s)$ growing like $s^{1.9}$, where $s$ is the distance measured along the direction of source propagation. That $\mathrm{f}(\mathrm{s})$ is growing faster than the first power of $\mathrm{s}$ is a consistent behaviour for modes of different radial order, independent of the assumed $T$ values.

DETERMINATION OF THE SOURCE TIME FUNCTION Once we know $f(s)$, then we can find the source time function using the moment $m(t)$ of an equivalent point double couple which can be estimated from the observed amplitude and phase of spectral peaks. As shown in Paper 1, under the assumption that the shape of the source time function $d(t)$ is common to all the sources points, the moment function $m(t)$ may be expressed as the convolution of $d(t)$ and $f(t)$, where $f(t)$ is considered as 
a function of the source propagation time $t$ instead of distance $s$. We can write

$$
m(t)=f(t) * d(t)
$$

or in the frequency domain

$$
M(\omega)=F(\omega) \cdot D(\omega)
$$

The absolute value of $\mathrm{M}(\omega)$ for periods longer than $160 \mathrm{sec}$ is reproduced in figure 9 from Mendiguren (1972). It is the average value computed from spectral peak amplitudes measured separately at single stations. The corresponding Fourier phase delays $\phi$ divided by $\omega$, shown in figure 10 , were measured at the frequencies corresponding to each spectral peak after stacking of spectra. The average value of $\phi / \omega$ is almost constant for periods above $150 \mathrm{sec}$. The average value of all measurements is $-30.8 \pm 0.6 \mathrm{sec}$. Also the corresponding value of $\phi / \omega$ for $F(\omega)$ is almost constant for periods above $150 \mathrm{sec}$ and equal to $27.8 \mathrm{sec}$.

Numerical tests with other possible shapes of $f(t)$, within the uncertainties of $T$, $T_{1}, R_{1}$ and $R_{2}$, indicate that $\phi / \omega$ for $F(\omega)$ is known within $\pm 2 \mathrm{sec}$.

Therefore, at long period, equation (2) gives for the phase spectra

$$
(\phi / \omega)_{\mathrm{D}}=(\phi / \omega)_{\mathrm{M}}-(\phi / \omega)_{\mathrm{r}}=-3 \pm 2.1 \mathrm{sec} .
$$

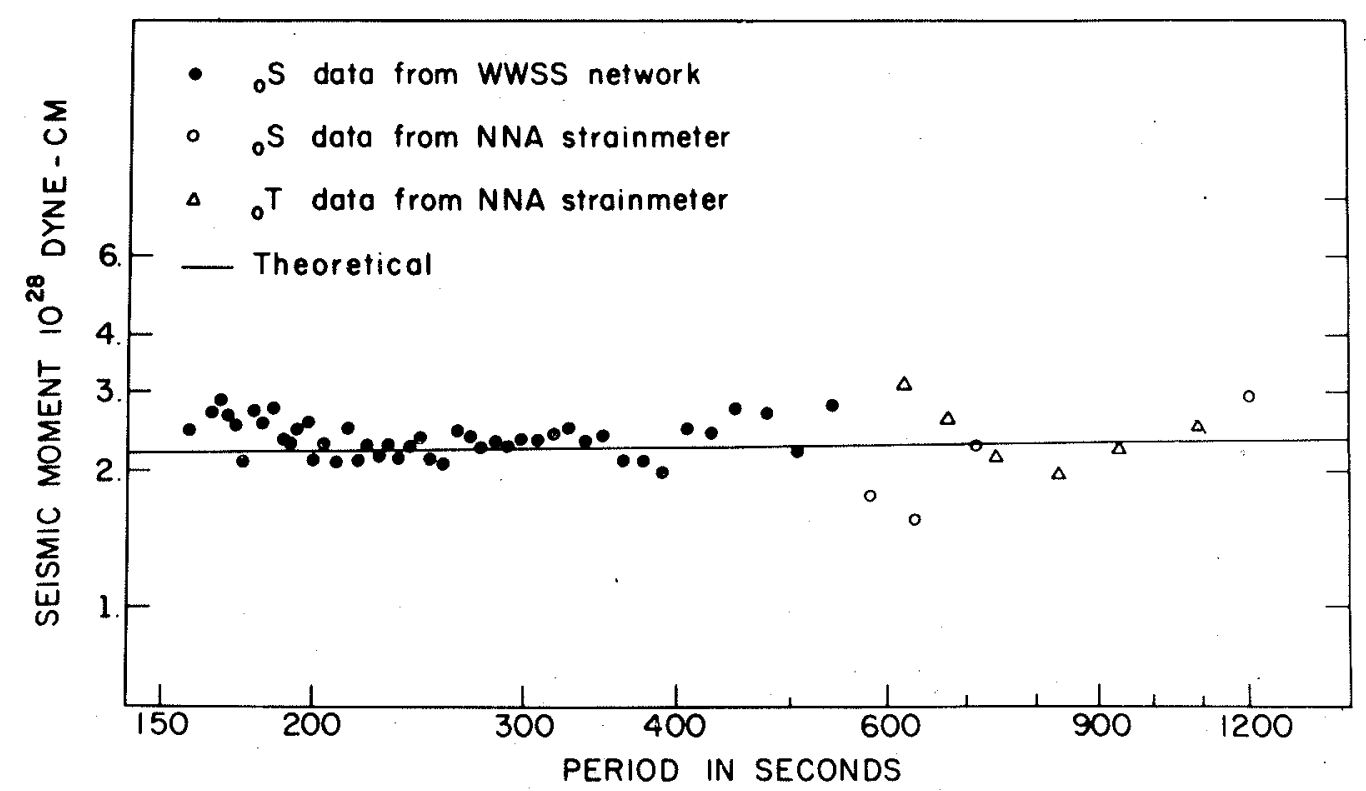

Figure $9-$ Absolute value of the Fourier transform of the time derivative of $m(t)$

Since the known frequency range of $M(\omega)$ is limited, $d(t)$ cannot be recovered completely. To overcome this limitation we assume that $d(t)$ has the form.

$$
d(t)=1-e^{-k t}
$$


and determine the parameter $\mathrm{k}$ such that $(\phi / \omega)_{\mathrm{D}}=-3 \mathrm{sec}$ at long period. $k=0.33 \mathrm{sec}^{-1}$ gives the best fit and the corresponding rise time is $7 \pm 3.5 \mathrm{sec}$. Figure 8 shows $d(t), f(t)$ and their convolution $m(t)$. The resulting $M(\omega)$ is compared to the observed one in Fig. 9. It should be remarked that $f(t)$ was determined independently of the source origin time, while later $d(t)$ was determined assuming that the radiation started at $\mathbf{P}$ wave origin time. Thus the available long period data for the double couple component of the source can be explained by a function $d(t)$ shaped as a ramp having $7 \mathrm{sec}$ rise time, without any precursory motion.

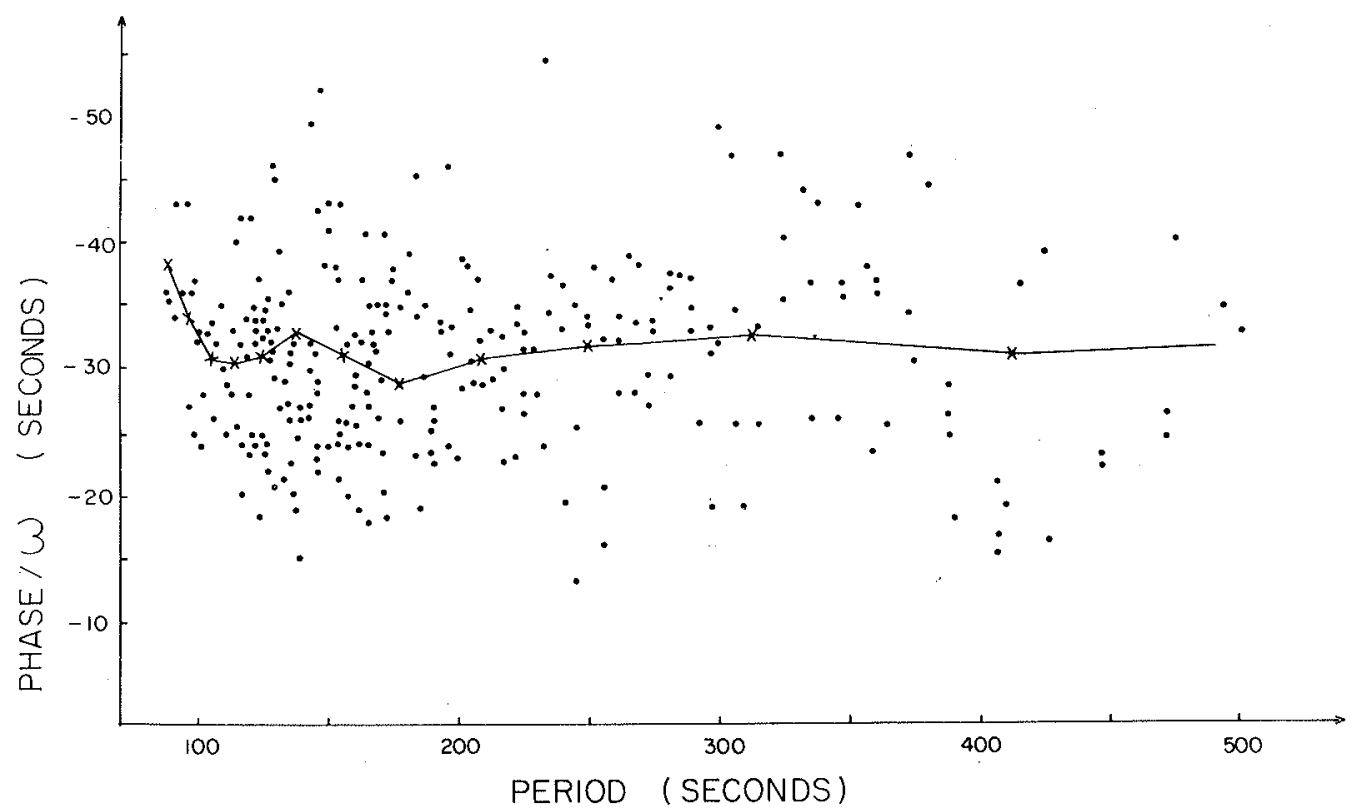

Figure $10-$ Fourier phase of $\mathrm{m}(\mathrm{t})$ divided by $\omega$ as a function of period. Crosses indicate average values of equal intervals in frequency

KINEMATICS OF THE SOURCE PROCESS Our method for finding the source parameters can reveal only the horizontal component of the source propagation. Therefore, the actual propagation distance can be greater than $153 \mathrm{~km}$.

The corresponding horizontal source propagation velocity, computed as the ratio of propagation distance to rupture time is $153 / 40=3.8 \mathrm{~km} / \mathrm{sec}$, or $66 \%$ of the shear velocity for the HB1.6 earth model used in this study (Haddon and Bullen, 1969). It is lower than the rupture velocities determined by Oike (1969), $4.6 \mathrm{~km} / \mathrm{sec}$, and Chandra (1970), $4.7 \mathrm{~km} / \mathrm{sec}$, but higher than $2.4 \mathrm{~km} / \mathrm{sec}$ found by Fukao (1972), all of them for deep earthq'iakes.

In fact the $3.8 \mathrm{~km} / \mathrm{sec}$ includes only the horizontal component of the source propagation. If there was any vertical component in the source propagation, the total velocity should be higher than $3.8 \mathrm{~km} / \mathrm{sec}$.

The direction of the source propagation was determined as $N 150^{\circ} \mathrm{E}$. This is in good agreement with the null axis of the $\mathbf{P}$ wave fault plane solution, which gave a nearly vertical presstre axis and $\mathrm{x}$ nearly horizontal tension axis. 
This earthquake is the first instrumentally located deep earthquake in Colombia. As shown in Fig. 11, the source propagated over $153 \mathrm{~km}$ in the direction to the more active deep seismic region further south on western Brazil. It appears, then, that the downgoing slab is continuous between the two regions and it actually guided the rupture propagation. If the rupture was forced to propagate along the axis of the lithosphere it would imply that the rupture "sensed" or reached the lithosphere boundary and did not propagate into the surrounding mantle. This agrees with the idea that even at $650 \mathrm{~km}$ depth the slab remains rheologically distinct from the surrounding mantle. While the slab sustains stresses which are eventually released as earthquakes, the surrounding mantle yields plastically. It also implies that the width of the ruptured zone should be comparable to the width of the slab at this depth.

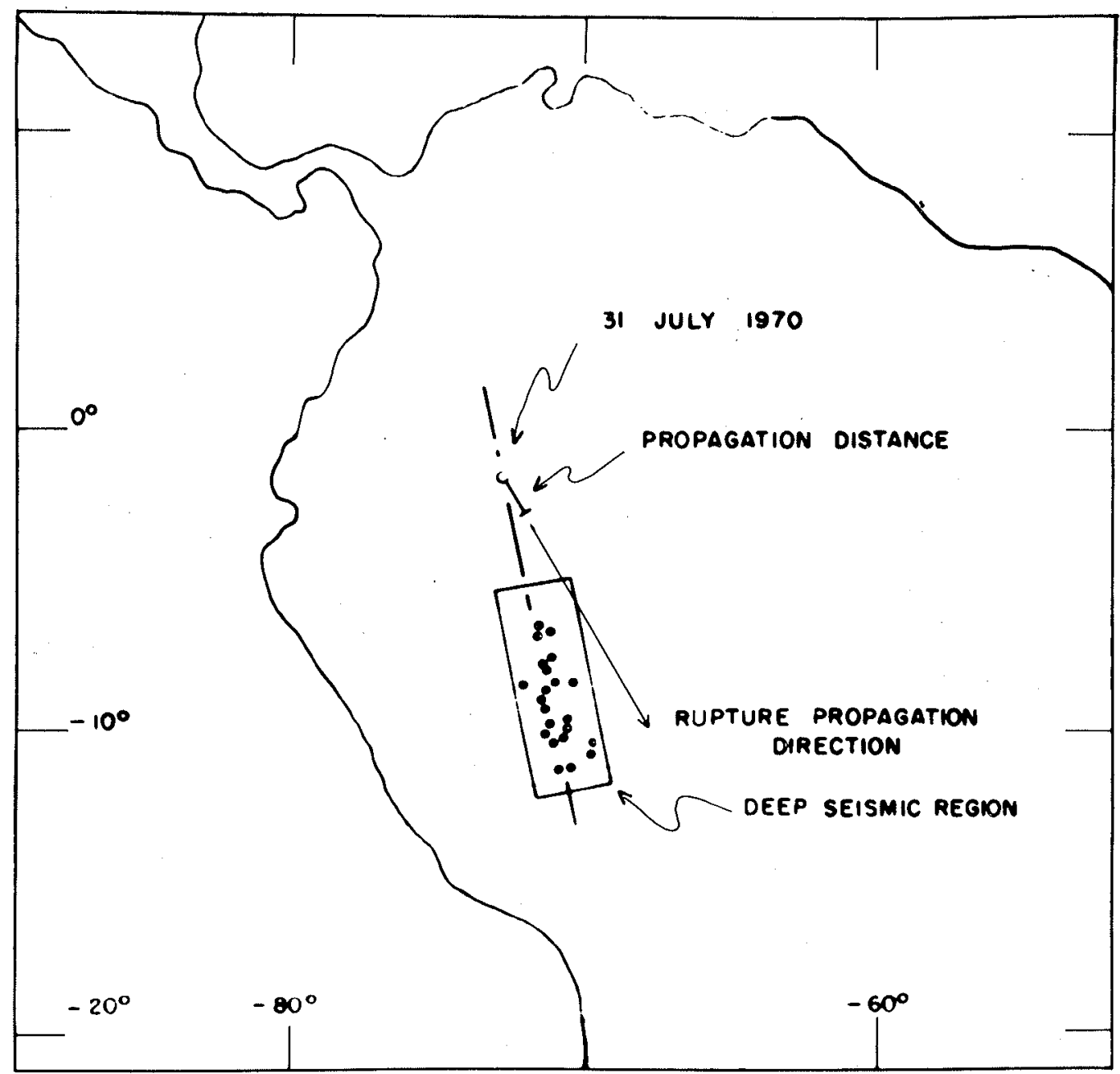

Figure 11 - Epicenter location, rupture propagation distance and azimuth for the 1970 deep Colombian event in relation to the deep seismic region of western Brazil 
This picture of a source extending over the whole width of the lithosphere is similar to that suggested by Kanamori (1971) for the shallow Sanriku earthquake of 1933, by Fukao (1972) for a sequence of deep western Brazil earthquakes, and by Billington and Isacks (1975) for a group of deep Tonga earthquakes.

From the length of hypothetical fault, Fukao estimates the thickness of the slab to be about $60 \mathrm{~km}$ at a depth of $600 \mathrm{~km}$, and Billington and Isacks give a minimum estimate of the thickness to be $35 \mathrm{~km}$ at the same depth. Since the seismic zone studied by Fukao is close to the hypocenter of our earthquake (it lies in the rectangular area shown in' Fig. 11), we shall assume that the thickness of the slab ruptured by our earthquake was also $60 \mathrm{~km}$.

There are accumulating evidence (Chandra, 1970; Fukao, 1970; Mikumo, 1969, 1971 a, b; Oike, 1969; Billington and Isacks, 1975; Aki, 1972; Wyss and Shamey, 1975) supporting the idea that deep earthquakes are caused by the slip on a fault plane just like shallow ones. Fukao (1972) presents such a case for the western Brazil earthquake of 1963 by showing that all the features of observed $P$ wave forms may be explained by a focal process in which rupture nucleates at a point, and a semi-circular rupture front proceeds to sweep a fan-shaped fault area.

The spatial source-intensity function $f(s)$ obtained for the Colombian earthquake by our method shows a feature which is expected precisely for such a growth of fault area into a fan-shape. According to the $\mathrm{P}$ wave fault plane solution, if the fault model applies, this earthquake is due to predominantly a dip-slip normal faulting on an incline fault plane. Let us suppose that the slip starts at a point, a semi circular rupture front propagates over the distance of $153 \mathrm{~km}$ and the fault area spreads into a fan-shape with the final width of $60 \mathrm{~km}$. This is a rather long and narrow fault, in which the width increases proportionally to the propagation distance s and the amount of slip increases proportionally to the width for a uniform stress drop. Since the source intensity is proportional to the product fo fault area and amount of slip, it will increase with the propagation distance as $\mathrm{s}^{2}$. This is exactly what we observed. Another feature of the source intensity function common to the western Brazil earthquake studied by Fukao is the abrupt stopping of the faulting indicated by the sharp drop of $f(t)$ shown in Fig. 8 .

Let us now estimate the amount of slip and stress drop. The seismic moment was obtained earlier in paper M.72 as $2.32 \times 10^{2 *}$ dyne-cm. Following Aki (1966), we find the average slip from the moment $M_{*}$, rigidity $\mu$ and fault area $S$ as

$$
\begin{aligned}
\overline{\Delta \mu} & =\frac{\mathrm{M}_{u}}{\mu \mathrm{S}} \\
& =\frac{2.32 \times 10^{2 \mathrm{~s}}}{1.43 \times 10^{12}} \times \frac{10^{5}}{1 / 2 \times 153 \times 10^{5} \times 60 \times 10^{3}} \\
& =360 \mathrm{~cm} .
\end{aligned}
$$

Since the fault length was a minimum estimate, the above value of average slip may be an overestimate. Using the formula of Starr (1928), we find the stress drop to be 


$$
\begin{aligned}
\Delta \sigma & =\frac{16}{3 \pi} \mu \frac{\overline{\Delta \mu}}{\mathrm{W}} \\
& =\frac{16}{3 \pi} \times 1.43 \times 10^{12} \times \frac{360}{30 \times 10^{5}} \\
& =300 \mathrm{bars}
\end{aligned}
$$

where $w$ is the fault widht in the middle of the fault length.

In opposition to the fault model of deep earthquakes, several seismologists favored one or other kind of volume sources involving phase transformation, such as Matuzawa (1953), Benioff (1963), Evison (1963), Randall (1964), Dennis and Walker (1965), Archambeau (1968), Randall and Knopoff (1970) and Knopoff and Randall (1970), although the observational support for these volume source models are less convincing than for the fault model. Here, we shall show that our data can be explained by a volume source as reasonably as by the fault model.

Let us simulate a volume source by a simple set of imaginary cutting, straining and welding operations (Eshelby, 1957). First, cut round the volume and remove it from the matrix. Let the body undergo transformational permanent strain $\Delta \mathrm{e}_{\mathrm{ij}}$ such as phase transformation. Apply surface tractions $-v_{j} c_{i j p q} \Delta \mathrm{e}_{\mathrm{pq}}=-\nu \Delta \tau_{\mathrm{ij}}$ which will restore the volume to its original form, where $v$ is the normal to the surface of the volume and $c_{i j p q}$ is the elastic constant relating the stress and strain components. Then we put the body back in the hole in the matrix and join the matrix across the cut. The stress is now zero in the matrix and is $-\Delta \tau_{i j}$ in the inclusion volume. If we let the stress discontinuity disappear, it will generate an elastic-field in the matrix. This elastic field is equivalent to the one caused by the application of traction discontinuity $-v \Delta \tau_{i j}$ across the surface of the inclusion volume.

The above process can be extended to a dynamic case of seismic wave generation, by a successive transformational strain applied quasi-statically to an internal volume. The equivalent body force to such a traction-discontinuity across the surface $S$ of the inclusion is given by Burridge and Knopoff (1964) as

$$
\mathrm{e}_{\mathrm{i}}=\int_{\mathrm{s}} \mathrm{d} \sum_{\zeta} \quad v_{j} \Delta \tau_{\mathrm{ij}} \delta(x, \zeta)
$$

For an infinitesimal volume surce, this body force distribution is equivalent to a set of dipoles and couples with the moment tensor given by

$$
\mathrm{M}_{\mathrm{ij}}=\Delta \tau_{\mathrm{ij}} \mathrm{V}
$$

Where $\mathrm{V}$ is the volume inclusion. See also Backus and Mulcahy (1976). This equation, for a special case of transformational shear strain in a sphere, was obtained earlier by Randall (1966) and discussed by Aki and Tsai (1972) in relation to the tectonic stress release by underground nuclear explosions. 
Our observations on the Colombian earthquake may be explained by a transformational shear strain inside a cone shaped body. If the transformation starts at the apex and spreads in the growing cone, the source intensity will increase proportionally to the square of the propagation distance in agreement with observation. We can estimate the transformational stress and strain from the seismic moment and the volume of the cone. Since the final height of the cone is $153 \mathrm{~km}$ and the radius of the base is $30 \mathrm{~km}$, we have

$$
\begin{aligned}
\dot{\Delta \tau} & =\frac{\mathrm{M}_{\mathrm{o}}}{\mathrm{V}} \\
& =\frac{2.32 \times 10^{28}}{1 / 3 \pi\left(30 \times 10^{5}\right)^{2} .153 \times 10^{5}} \\
& =160 \text { bars } \\
\Delta \mathrm{e} & =\frac{\Delta \tau}{\mu} \\
& =\frac{16 \times 10^{7}}{1.43 \times 10^{12}} \\
& =11 \times 10^{-5}
\end{aligned}
$$

Thus, the volume source described above explains our data very reasonably. We prefer, however, the fault model because of the stronger observational support from studies using higher spatial resolving power such as the consistency among the nodal plane of main-shock first motion and planar concentrations of sources of stopping phases (Fukao, 1972) and foci of aftershocks (Billington and Isacks, 1975; Wyss and Shamey, 1975).

The apparent average stress $\eta\langle\sigma\rangle$, found in M.72, is 5.6 bars. Therefore we may estimate an upper limit for the seismic efficiency as follows

$\eta<\frac{\eta\langle\sigma\rangle}{\Delta \sigma / 2}=\frac{5.6}{300 / 2}=0.04$

In summary the source parameters found for the deep Colombian shock are the following

Seismic moment $M_{\text {o }}$

Magnitude $m_{b}$

Rupture azimuth

Rupture length

Average fault width

Average horizontal rupture velocity
$2.32 \times 10^{28}$ dynes $\mathrm{cm}$ 7.1

$\mathrm{N} 150^{\circ} \mathrm{E} \pm 15^{\circ}$

$153 \pm 30 \mathrm{~km}$

$30 \mathrm{~km}$

$3.8 \mathrm{~km} / \mathrm{sec}$. 
Fault area

Rupture time duration

Average dislocation

Rise time

Stress drop

Apparent average stress

Seismic efficiency

Transformational stress for volume source model

Transformational strain for volume source model
$4600 \mathrm{~km}^{2}$

$40 \mathrm{sec}$

$360 \mathrm{~cm}$

$7 \pm 3.5 \mathrm{sec}$.

300 bar

5.6 bar

$<0.04$

160 bar

$11 \times 10^{-5}$

THE IMPLOSIVE COMPONENT OF THE SOURCE MOMENT TENSOR Studying the free oscillation data from the same Colombian earthquake, Gilbert and Dziewonski (D.G.74 and G.D.75) observed an isotropic component of the moment tensor which they related to an implosive source starting earlier than the $\mathbf{P}$ wave origin time, only detectable at low frequencies and attributed to a precursory phase transformation.

Given the implications of this finding on our knowledge on the properties of the mantle, we decided to perform an independent inversion of observed free oscillation data and some numerical experiments to verify if the implosive component could be artificially introduced by random noise or by some assumption in the inversion procedure.

Our data was a set of 1102 observations of well defined $S_{11}$ spectral peaks in the vertical component of 65 WWSS stations. The amplitude of each spectral peak was measured directly on the spectra and corrected for instrument response, attenuation and record length. For further details on data treatment see $M .73 \mathrm{~b}$.

In a first inversion of those data the solution was left unconstrained while in a second inversion the condition of a pure deviatoric source, $\Sigma M_{i i}=0$, was imposed to the solution.

Fig. 14 shows the seismic moment eigenvector solutions for the constrained and unconstrained cases compared to the M.73b solution obtained from $P$ wave observations. The isotropic part was taken out from the unconstrained solution. Both solutions are quite close to each other but they would require about $20^{\circ}$ rotation in azimuth to match the $\mathrm{P}$ wave solution.

Table 1 shows the corresponding seismic moment tensor components for the constrained and unconstrained cases, their probable error, the isotropic component, the difference $\left(M_{\phi \phi}-M_{\theta \theta}\right)$, the standard error of the observations and the coefficient $R^{2} . R^{*}$ is the coefficient of multiple determination (Walpole and Myers, 1972) which is a measure of the proportion of the observations explained by the fitted model. $\mathrm{R}^{2}$ is almost the same for both constrained and unconstrained solutions. Similarly we should not that the standard deviation of the observations is approximately the same in both cases. This means that a pure deviatoric source model or a source model includiing an isotropic component explain the data equally well. Both models are equally satisfactory and from a statistical basis we may not reject the model including an implosive component.

Next we will analyze an aspect of the inversion procedure which can explain why both models fit the data equally well. It is the equivalence in radiation between a vertical dipole and a couple of horizontal dipoles at $90^{\circ}$ of each other, as discussed as follows. 
Table 1

\begin{tabular}{|c|rrrrrrrrrr|}
\hline Case & $\mathrm{M}_{\mathrm{rr}}$ & $\mathrm{M}_{\theta \theta}$ & $\mathrm{M}_{\phi \phi}$ & $\mathrm{M}_{\mathrm{r} \theta}$ & $\mathrm{M}_{\theta \phi}$ & $\mathrm{M}_{\phi \mathrm{r}}$ & $\Sigma_{\mathrm{ii}}$ & $\mathrm{M}_{\theta \theta}-\mathrm{M}_{\phi \phi}$ & $\mathrm{R}^{2}$ & $\sigma_{\mathrm{O}-\mathrm{r}}$ \\
\hline 1 & -864 & -621 & 344 & 141 & 78 & -309 & -1141 & -965 & 0.53 & 149 \\
Free & 90 & 162 & 177 & 18 & 49 & 23 & & & & \\
\hline 2 & -618 & -192 & 810 & 139 & 81 & -312 & 0 & -1002 & 0.52 & 151 \\
$\Sigma \mathrm{M}_{\mathrm{ii}}=0$ & 24 & 59 & 68 & 18 & 50 & 23 & & & & \\
\hline
\end{tabular}

The real part of the moment rate tensor components for $S_{n}$ modes from $n 13$ to 35 . "Free" and $\Sigma M_{i i}=0$ indicate the unconstrained and constrained solutions respectively. The lower figures are the standard deviation of the solutions. $\Sigma \mathrm{M}_{\mathrm{ii}}$ is the isotropic component. $\sigma_{O-\mathrm{T}}$ is the standard deviation of the observed amplitudes with respect to the theoretical ones. $R^{2}$ is the coefficient of multiple determination.

The components of the moment tensor $\mathrm{M}_{\mathrm{i}}($ Gilbert, 1970), are related to the free oscillation amplitudes of a single mode by the equation

$$
\mathrm{U}(\theta, \phi, \mathrm{t})=\mathrm{e}^{-(\omega \mathrm{\omega} 2 \omega)} \quad \cos \omega \mathrm{t} \sum_{i}^{6} \mathrm{a}_{i} \mathrm{M}_{\mathrm{i}}
$$

Since any single mode is expressed by 5 independent constraints $M_{m}$ in equation (1) of paper 1, the system (6) with 6 unknowns cannot have a unique solution for data corresponding to a single mode, even if a large number of observations is available. To illustrate this, we may note that a unit component $M_{r r}$ radiates exactly as a combination $-A\left(M_{\theta \theta}+M_{\phi \phi}\right)$ where

$$
\mathrm{A}=\frac{2 \lambda}{\lambda+2 \mu}\left(1-\frac{\mathrm{ry}_{2}}{\lambda\left(2 \mathrm{y}_{1}-\mathrm{N}^{2} \mathrm{y}_{3}\right)}\right)
$$

where Saito's (1967) notation has been used.
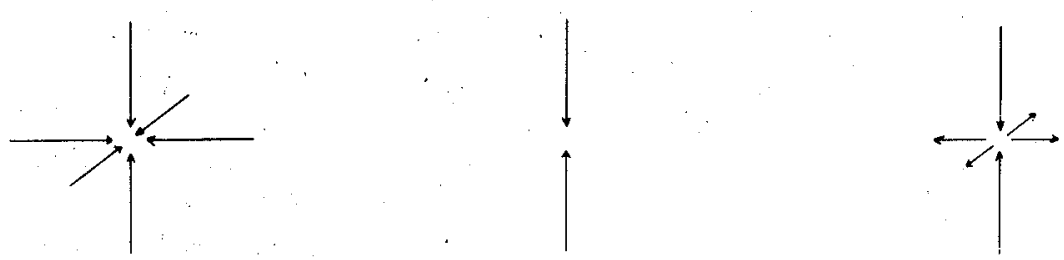

$-(M r r+M \theta \theta+M \varnothing \sigma) \equiv-(1-1 / A) M r r \equiv \frac{2(A-1)}{2 A+1}(-M r r+1 / 2 \cdot(M \theta \theta+M \varnothing \sigma))$

Figure 12 - An implosion, a vertical dipole and their combination (compensated linear vector dipole) produce similar radiation. 


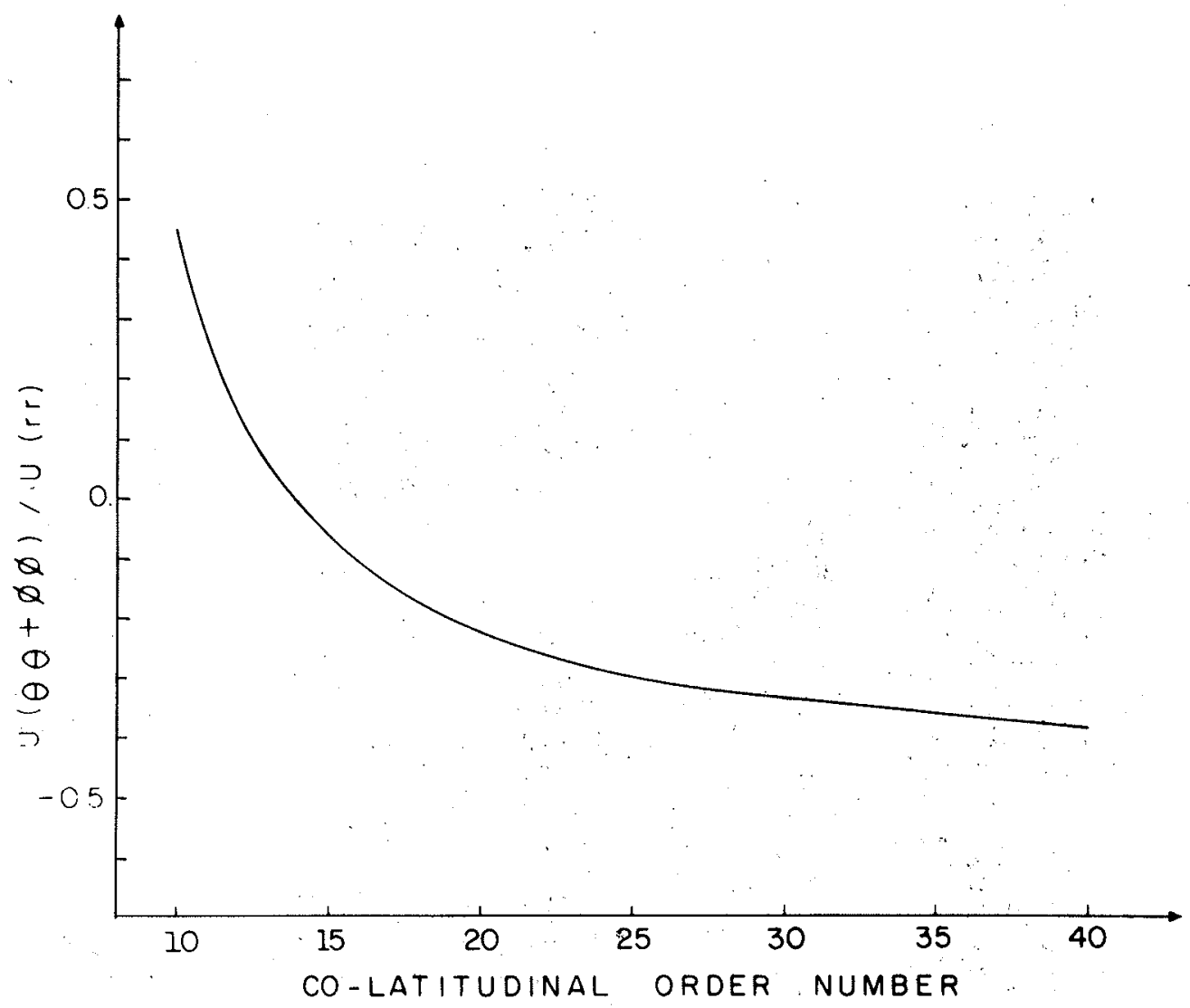

Figure $13-$ Value of $-A^{-1}$ for $S_{0}$ modes at $650 \mathrm{~km}$ depth. For $\mathrm{n}=14$, the set $\left(M_{\theta \theta}+M_{\phi \phi}\right)$ does not radiate

Therefore, for a single mode, an implosive source $\left(M_{r r}=M_{\phi \phi}=M_{\theta \theta}\right)$ radiates as $(1 / \mathrm{A}-1) \mathrm{M}_{\mathrm{rr}}$ or as $2(\mathrm{~A}-1) /(2 \mathrm{~A}+1)$ times a vertical compensated linear vector dipole (Knopoff and Randall, 1970), as illustrated in Figure 12. Note that while the implosion is purely isotropic the compensated linear vector dipole has no isotropic component. Then from a set of $M_{\text {ii }}$ satisfying (6) it is possible to shift $M_{r r}$ component to $M_{\theta \theta}$ and $M_{\phi \phi}$ and still satisfy the observations for a single mode. Figure 13 shows the value of $A^{-1}$ for $S_{n}$ modes at low frequency. For $n$ around 14 the set $\left(M_{\theta \theta}+M_{\phi \phi}\right)$ will not radiate at all, and it could be arbitrarily added to a solution of equation (6). That possible trade off between $M_{r r_{i}}$ and $\left(M_{\theta \theta}+M_{\phi \phi}\right)$ is what allows to explain the $S_{n}$ data equally well with a deviatoric source or with a source containing an implosion. A closer look at values in Table 1 shows that while the non-diagonal terms $\mathrm{M}_{\mathrm{ij}}$ are almost unchanged, there is a trade off between $M_{r r}$ and $\left(M_{\phi \phi}+M_{\theta \theta}\right)$ when passing from the unconstrained to the constrained solution. The possibility of a trade-off between $\mathrm{M}_{\mathrm{ij}}$ components is also reflected in the component correlation matrices given in Table 3. The correlation for $\mathbf{M}_{\mathrm{it}}$ pairs is larger than for pairs including non diagonal components $M_{i j}$. The restriction $\Sigma M_{i j}=0$ does not change that pattern. In order to test if the same trade off between diagonal terms of the moment tensor 
could take place when higher modes were included, we performed the following experiment. Excitation corresponding to 103 spheroidal modes of radial order 0 to 6 for periods between 200 and 500 seconds were computed for 65 WWSS stations used in D.G.75. A random noise was added to those excitations and later they were used as "observations" to solve (6) for the moment tenisor components.

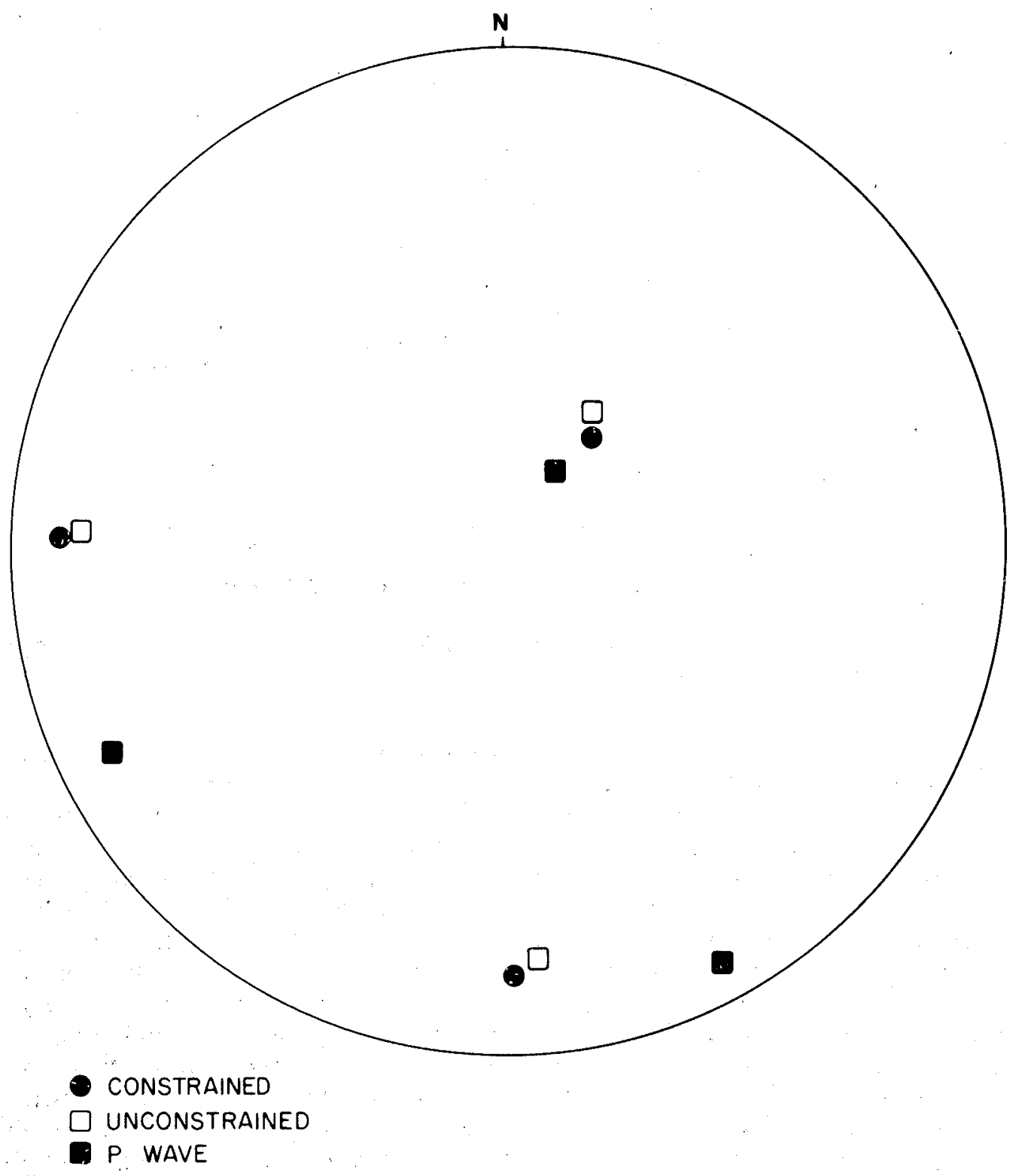

Figure 14 - Eigenvectors of the seismic moment tensor for the constrained andunconstrained solutions obtained from free oscillation data compared to the $\mathrm{P}$ wave solution 
Noise level was adjusted to obtain a variance of observational errors similar to that obtained with real data. For a source consisting of a combination of a double couple and an implosive source, the unconstrained inversion of (6) recovered both parts exactly, as shown under case 3 in Table 2 . This implies that a random noise does not introduce any systematic error, in either isotropic or deviatoric components, for the set of data available for the Colombian shock. In a subsequent experiment the same set of data used in case 3, corresponding to a double couple plus an implosion, was inverted under the condition $\Sigma M_{i i}=0$. The results are shown under case 4 in Table 2. The standard deviation of observations is approximately the same for both cases 3 and 4 . The non-diagonal terms $\mathbf{M}_{\mathrm{ij}}$ remained also unchanged, while there was a trade off between $M_{n}$ and $\left(M_{\theta \theta}+M_{\phi \phi}\right)$ which allowed to explain the data equally well, on a statistical basis, with or without the inclusion of an isotropic source. This result is similar to that obtained with the real data of $S_{0}$ modes. Therefore we conclude that if the source contained a low frequency implosive component the available data could be equally well explained by a pure deviatoric source model. The trade-off between $M_{i i}$ components is also reflected in the corresponding correlation matrices shown in Table 3.

The inclusion of the constraint $\Sigma M_{i i}=0$ reduced the standard deviation of the diagonal tensor components by a factor of 2 , see Table 2 . The standard deviations are much smaller than the absolute value of the seismic moment components for both cases, constrained and unconstrained. The same was observed in G.D.75 results. This means that the solutions are significant for the assumed model, but their smallness can not be taken as proof of the validity of the assumed model itself.

Table 2

\begin{tabular}{|c|rrrrrrrrrr|}
\hline Case & $\mathrm{M}_{\mathrm{rr}}$ & $\mathrm{M}_{\theta \theta}$ & $\mathrm{M}_{\phi \phi}$ & $\mathrm{M}_{\mathrm{r} \theta}$ & $\mathrm{M}_{\theta \phi}$ & $\mathrm{M}_{\phi_{1}}$ & $\mathrm{M}_{\mathrm{ii}}$ & $\mathrm{M}_{\theta \theta}-\mathrm{M}_{\phi \phi}$ & $\mathrm{R}^{2}$ & $\sigma_{\mathrm{O}-\mathrm{T}}$ \\
\hline 3 & -1000 & 31 & 637 & 299 & -399 & -313 & -331 & -606 & 0.75 & 73 \\
Free & 17 & 25 & 27 & 6 & 15 & 8 & & & & \\
\hline 4 & -911 & 148 & 763 & 298 & -338 & -315 & 0 & -615 & 0.75 & 73 \\
$\Sigma \mathrm{M}_{\mathrm{ii}}=0$ & 7 & 15 & 16 & 6 & 15 & 8 & & & & \\
\hline
\end{tabular}

Moment rate tensor components for the free and constrained inversions. Data form 65 WWSS stations and 103 spheroidal modes, or 6695 observations are involved in those inversions. Data correspond to modes of radial order from 0 to 6 and periods between 200 and 500 seconds, for a source consisting of a double couple plus an implosion. For further details see caption of Table 1 .

Next we analyze if the inversion of radiation data corresponding to a pure deviatoric source could result in a solution moment tensor with an isotropic component. Using the same set of stations and modes as in case 3 and 4 we computed the theoretical radiation for a pure double couple source. A random noise was added to the radiation and later it was used as "observations" in the inversion scheme. The inversion recovered the double couple exactly without any isotropic component. In a subsequent experiment a double couple plus a compensated linear vector dipole was taken as the source. The inversion of this data did not result in any significant isotropic component. From this experiment we conclude that if the source mechanism of 
the Colombian shock was pure deviatonc, the available data is sufficient to avoid the possibility that a trade off among the moment tensor diagonal components could result in a spurious isotropic component. Therefore, the inversion of data corresponding to a source including an isotropic component led to equally satisfactory model solutions including or not an isotropic component, depending on the inversion constraints. But the opposite is not true, namely, the inversion of data corresponding to a pure deviatoric source will not result in an isotropic component, even in the presence of random noise. It is understood that we are assuming a data set equivalent to that available for the Colombian shock.

Table 3

\begin{tabular}{|c|c|c|c|c|c|c|c|}
\hline & $\mathrm{r} \theta$ & $\theta \phi$ & $\phi \mathrm{r}$ & $\mathrm{rr}$ & $\theta \theta$ & $\phi \phi$ & \\
\hline $\begin{array}{c}\text { Case } \\
1 \\
\text { Free } \\
S_{0}\end{array}$ & 1.00 & $\begin{array}{r}-0.05 \\
1.00\end{array}$ & $\begin{array}{r}-0.04 \\
-0.12 \\
1.00\end{array}$ & $\begin{array}{r}-0.05 \\
-0.05 \\
-0.06 \\
1.00\end{array}$ & $\begin{array}{r}-0.07 \\
-0.07 \\
-0.03 \\
0.90 \\
1.00\end{array}$ & $\begin{array}{r}0.01 \\
-0.01 \\
-0.14 \\
0.81 \\
0.73 \\
1.00\end{array}$ & $\begin{array}{l}r \theta \\
\theta \phi \\
\phi r \\
r r \\
\theta \theta \\
\phi \phi\end{array}$ \\
\hline $\begin{array}{c}\text { Case } \\
\Sigma M_{i \mathrm{ij}}^{2}=0 \\
{ }_{0} S_{n}\end{array}$ & 1.00 & $\begin{array}{r}-0.05 \\
1.00\end{array}$ & $\begin{array}{r}-0.04 \\
-0.13 \\
1.00\end{array}$ & $\begin{array}{r}-0.04 \\
-0.01 \\
0.07 \\
1.00\end{array}$ & $\begin{array}{r}-0.11 \\
-0.08 \\
0.15 \\
0.13 \\
1.00\end{array}$ & $\begin{array}{r}0.11 \\
0.08 \\
-0.16 \\
-0.52 \\
-0.92 \\
1.00\end{array}$ & $\begin{array}{l}\mathrm{r} \theta \\
\theta \phi \\
\phi \mathrm{r} \\
\mathrm{rr} \\
\theta \theta \\
\phi \phi\end{array}$ \\
\hline $\begin{array}{c}\text { Case } \\
3 \\
\text { Free } \\
S_{n} \text { to } \\
{ }_{6} S_{n}\end{array}$ & 1.00 & $\begin{array}{r}-0.04 \\
1.00\end{array}$ & $\begin{array}{r}-0.03 \\
-0.09 \\
1.00\end{array}$ & $\begin{array}{r}-0.03 \\
-0.06 \\
-0.02 \\
1.00\end{array}$ & $\begin{array}{r}-0.07 \\
-0.04 \\
0.04 \\
0.76 \\
1.00\end{array}$ & $\begin{array}{r}0.04 \\
0.06 \\
-0.11 \\
0.58 \\
0.30 \\
1.00\end{array}$ & $\begin{array}{l}\mathrm{r} \theta \\
\theta \phi \\
\phi \mathrm{r} \\
\mathrm{rr} \\
\theta \theta \\
\phi \phi\end{array}$ \\
\hline $\begin{array}{c}\text { Case } \\
4 \\
\sum M_{i i}=0 \\
S_{n} \text { to } \\
S_{6} S_{n}\end{array}$ & 1.00 & $\begin{array}{r}-0.04 \\
1.00\end{array}$ & $\begin{array}{r}-0.03 \\
-0.09 \\
1.00\end{array}$ & $\begin{array}{r}-0.03 \\
-0.03 \\
0.05 \\
1.00\end{array}$ & $\begin{array}{r}-0.09 \\
-0.08 \\
0.12 \\
0.12 \\
1.00\end{array}$ & $\begin{array}{r}0.09 \\
0.09 \\
-0.13 \\
-0.51 \\
-0.91 \\
1.00\end{array}$ & $\begin{array}{l}\mathrm{r} \theta \\
\theta \phi \\
\phi \mathrm{r} \\
\mathrm{rr} \\
\theta \theta \\
\phi \phi\end{array}$ \\
\hline
\end{tabular}

Correlation matrices for moment tensor components. In cases 1 and 2 only $\mathrm{S}_{\mathrm{n}}$ modes were treated. In cases 3 and $4{ }_{0} S_{n}$ and higher modes till ${ }_{6} S_{n}$ were treated. In cases 1 and 3 the solution was unconstrained, while in cases 2 and 4 the constraint $\Sigma M_{i i}=0$ was imposed to the solution.

At this point we should notice that both models, either the pure deviatoric or the model including an isotropic component can explain only about $50 \%$ of the variation in spectral peak amplitude, as indicated by the parameter $R^{2}$. This relatively 
poor fit is equivalent to the scatter in seismic moment values as determined from different spectral peaks. While part of the scattering is doubtless due to instrumental noise, probably the dominant is due to lateral heterogeneities of the earth. Luh and Dziewonski (1976) have shown that ellipticity and rotation of the earth produce a change in spectral peak amplitude which on the average is $30 \%$ of the amplitude corresponding to a non-rotating spherical earth. We should expect changes even larger if lateral heterogeneities were included. The overall effect would be the introduction of amplitude variation which could result in an artificial implosive component if the inversion is carried out assuming an spherical, non rotating, laterally homogeneous earth. This possibility is explored in a coming paper. At this point we conclude that when the free oscillation data for the Colombian shock is inverted assuming a laterally homogeneous earth, it yields a source with an isotropic component which could not be artificially introduced by random noise or some artifact of the inversion scheme.

Acknowledgements We thank Raul Madariaga for useful and inspiring discussions on this paper and on general subjects of seismic source mechanism. This study was supported partially by a grant from Conselho Nacional de Desenvolvimento Científico e Tecnológico of Brazil, and partially by the grant EAR73-00425 from the National Science Foundation.

\section{REFERENCES}

AKI, K. - 1966 - Generation and propagation of G waves from the Niigata earthquake of June 16, 1964, Part 2. Estimation of earthquake moment, released energy, and stressstrain drop from the G-wave spectrum. Bull. Earthq. Res. Inst., 44: 73-88.

AKI, K. - 1972 - Earthquake mechanism, in: A.R. Ritsema (ed.), The Upper Mantle, Tectonophysics, $14: 423-446$.

AKI, K. and TSAI, Y.B. - 1972 - Mechanism of Love wave excitation by explosive sources. J. Geophys. Res., 77: 1452-1475.

ARCHAMBEAU, C.B. - 1968 - General theory of elastodynamic source fields. Rev. Geophys., 6: 241-288.

BACKUS, G. and MULCAHY, M. - 1976 -- Moment tensor and other phenomenological descriptions of seismic sources, I. Continuous displacements, Geophys, J.R. Astron. Soc., 46: 341-361.

BENIOFF, H. - 1963 - Source wave forms of three earthquakes. Bull. Seism. Soc. Am., 53: 893-903.

BILLINGTON, S. and ISACKS, B.L. - 1975 - Identification of fault planes associated with deep earthquakes. Geophys. Res. Lett., 2: 63-66.

BURRIDGE, R. and KNOPOFF, L. - 1964 - Body force equivalents for seismic dislocations. Bull. Seism. Soc Am., 54: 1875-1888.

CHANDRA, U. - 1970 - The Peru-Bolivia border earthquake of August 15, 1963. Bull. Seisn. Soc. Am., 60: 639-646.

DENNIS, J. and WALKER, C.T. - 1965 - Earthquakes resulting from metastable phase transitions. Tectonophysics, 2: 401-407.

DZIEWONSKI, A.M. and GILBERT, F. - 1974 - Temporal variation of the seismic moment tensor and the evidence of precursive compression for two deep earthquakes. Nature, 247: $185-188$.

ESHELBY, J.D. - 1957 - The determination of the elastic ficld of an ellipsoidal inclusion and related problems. Proc. Roy. Soc. Lon., Ser. A, 241: 376-396.

EVISON, F.F. -- 1963 - Earthquakes and faults. Bull, Seism. Soc. Am., 53: 873-891. 
FUKAO, Y. - 1970 - Source process of a large deep focus earthquake as deduced from long period $\mathrm{P}$ and $\mathrm{S}$ waves. Bull. Earthq. Res. Inst., 48: 707-727.

FUKAO, Y. - 1972 - Source process of a large deep-focus earthquake and its Tectonic implications - the Western Brazil Earthquake of 1963. Phys. Earth Planet. Int., 5: $61-67$.

GILBERT, F. - 1970 - Excitation of the normal modes of the Earth by earthquake sour ces. Geophys. J. Roy. Astron. Soc., 22: 223-226.

GILBERT, F. and DZIEWONSKI, A.M. - 1975 - An application of normal mode theory to the retrieval of structural parameters and source mechanism from seismic spectra. Phil. Trans. Roy. Soc. Lon., 278: 187-269.

HADDON, R.A.W. and BULLEN, K. - 1969 - An Earth model incorporating free Earth oscillations data. Phys. Earth Planet. Int., 2: 35-49.

KANAMORI, H. - 1971 - Seismological evidence for a lithospheric normal faulting the Sanriku Earthquake of 1933. Phys. Earth Planet. Int., 4: 289-300.

KNOPOFF, L. and RANDALL, J. - 1970 - The compensated linear-vector dipole: A possible mechanism for deep earthquakes. J. Geophys. Res., 75: 4957-4963.

LUCH, P.C. and DZIEWONSKI, A.M. - 1976 -- Theoretical normal-mode spectra of a rotating elliptical earth. Geophys. J. Roy. Astron. Soc.

MATUZAWA, T. - 1953 - Feldtheorie der Erdbeben, Bull, Earthqu. Res. Inst., 31: 179-201.

MENDIGUREN, J.A. - 1972 - Source mechanism of a deep earthquake from analysis of world wide observation of free oscillations. Ph.D. Thesis, Massachusetts Institute of Technology, Cambridge, Mass.

MENDIGUREN, J.A. - 1973a - High-resolution spectroscopy of the Earth's free oscillations, knowing the source mechanism. Science, 179: 179-180.

MENDIGUREN, J.A. - 1973b - Identification of free oscillations spectral peacks for the 1970 July 31 , Colombian deep shock using the excitation criterium. Geophys. J. Roy. Astron. Soc., 33: 281-321.

MENDIGUREN, J.A. - 1977 - A numerical method to determine physical source parameters from free oscillation data. Geophys. J. Roy. Astron. Soc. (in press).

MIKUMO, T. - 1969 - Long period $P$ wave forms and the source mechanisms of intermediate earthquakes. J. Phys. Earth, 17: 169-192.

MIKUMO, T. - $1971 \mathrm{a}$ e b - Source process of deep intermediate earthquakes as inferred from long period $\mathrm{P}$ and $\mathrm{S}$ wave forms.

a. Intermediate-depth earthquakes in the southwest Pacific region. J. Phys. Earth, 19: 1-19;

b. Deep-focus and intermediate depth earthquakes around Japan. J. Phys. Earth, 19: 303-320.

OIKE, K. - 1969 - The deep earthquake of June 22, 1966 in Banda Sea; A multiple shock. Disaster Prov. Res. Inst., Kyoto Univ. Bull, 19: 55-65.

RANDALL, M.J. - 1964 - On the mechanism of earthquakes. Bull. Seism. Soc., Am., 54: $1283-1289$.

RANDALL, M:J. - 1966 - Seismic radiation from a sudden phase transition. J. Geophys. Res., 71: 5297-5302.

RANDALL, M.J. and KNOPOFF; L. - 1970 - The mechanism at the focus of deep earthquakes. J. Geophys. Res., 75: 4965-4976.

STARR, A.T. - 1928 - Slip in a crystal and rupture in a solid due to shear. Proc. Cambridge Phil. Soc., 24: 489-500.

WALPOLE, R.E. and MYERS, L.J. - 1972 - Probability and Statistics for Engineers and Scientists, Mac Millan Co.

WYSS, M. and SHAMEY, L.J. - 1975 - Source dimensions of two deep earthquakes estimated from aftershock and spectra. Bull. Seism. Soc. Am., 65: 403-409. 